\title{
Applying Pareto multi-criteria decision making in concurrent engineering: A case study of polyethylene industry
}

\author{
Akbar A. Tabriz ${ }^{\mathrm{a}}$, Ahmad Ahmadi ${ }^{\mathrm{b}}$, Mohammad Hassan Maleki ${ }^{\mathrm{b}}$, Mohammad Ali Afshari ${ }^{\mathrm{c}}$ and \\ Javad S. Moradi ${ }^{\text {d }}$
}

\author{
${ }^{a}$ Department of Accounting and Management, Shahid Beheshti University, Tehran, Iran \\ ${ }^{b}$ Department of Management, University of Tehran, Tehran, Iran \\ ${ }^{c}$ Departemtn of Science, Kar University, Qazvin, Iran \\ ${ }^{d}$ Department of Management, Islamic Azad University, Science \& Research Branch, Tehran, Iran
}

A T I C L E I N F $\quad$ AB S T A T

Article history:

Received January 292010

Received in revised form

24 March 2011

Accepted 26 March 2011

Available online

29 March 2011

Keywords:

concurrent engineering

Pareto MCDM

Pareto data

Pareto-compromise design

Pareto-competitive equilibrium
Concurrent engineering (CE) is one of the widest known techniques for simultaneous planning of product and process design. In concurrent engineering, design processes are often complicated with multiple conflicting criteria and discrete sets of feasible alternatives. Thus multi-criteria decision making (MCDM) techniques are integrated into CE to perform concurrent design. This paper proposes a design framework governed by MCDM technique, which are in conflict in the sense of competing for common resources to achieve variously different performance objectives such as financial, functional, environmental, etc. The Pareto MCDM model is applied to polyethylene pipe concurrent design governed by four criteria to determine the best alternative design to Pareto-compromise design.

(C) 2011 Growing Science Ltd. All rights reserved.

\section{Introduction}

Nowadays, global competition in providing new products is very intensive. The time needed for providing product is an important distinction between successful and unsuccessful companies. Successful companies learn how to manage time and technological advances. Concurrent engineering (CE) is one of the tangible progress in this field and it has evolved as a technique. In this technique, engineering product design and engineering process design are performed, simultaneously. The implementation of CE is based on teamwork to increase the efficiency of an organization. A specialized team normally is responsible for performing conceptual thinking, product design and production planning, simultaneously. The aim of this method requires individuals to consider all product life cycle factors which includes customers and suppliers' requirements such as performance, quality, cost, program implementation, maintenance (winner et al., 1988). A successful teamwork needs to incorporate people from different departments such as design, marketing, construction, purchase, financial engineers. The team begins its work from the first stage and continues the teamwork until the end of the project (Brookes \& Backhouse, 1998). A good communication plays an 
important role for success of a teamwork and it involves the relationship between human and computer and both (Kerishnan et al., 1997). There are some disadvantages on the implementation of CE when different people gather and wish to reach the same objective. For instance, it is difficult to overcome the barriers between design and manufacturing just by gathering people. Concurrent design also requires communication and flexibility, which is difficult in some cases to achieve. One alternative to overcome to such difficulties is to use MCDM techniques to find a good trade-off among various objectives (Hokkanen \& Salminen, 1993; Rahimi-Vahed, 2007). Agrell (1994) used MCDM technique to form a modern methodology for collaborating among various departments in the product development process. He presented a non-linear compromise programming algorithm with simplified operation as a support for his proposed methodology. Qi et al. (2009) proposed a case retrieval technique combined with similarity measurement and MCDM techniques for concurrent design. In their implementation, they used a hybridization of fuzzy similarity measurement (FSM) and fuzzy MCDM for case retrieval from historical cases for concurrent design. During the first stage, FSM uses triangular function to represent various fuzzy requirements, respectively, and measures the similarity, which helps remove less valuable cases. Then fuzzy MCDM is incorporated for the assessment of the most similar cases in terms of product criteria to pick out the most suitable case. They also implemented the proposed model to power transformer concurrent design, and reported that the proposed model could be useful for case retrieval. Liu (2011) used quality deployment function (QFD) and fuzzy MCDM for product design and development. In this study, Liu integrates fuzzy QFD and the prototype product selection system to present a product design and selection (PDS) approach. In fuzzy QFD, the $\alpha$-cut operation is used to measure the fuzzy set of each component. The method also uses engineering characteristics and the factors involved in product development for prototype product selection. The method also uses a fuzzy MCDM method to select the best prototype product.

Valle and Vasquez-Bustelo (2009) analyzed the link between the use of CE and success in new product development (NPD) under different circumstances of uncertainty and complexity, radical versus incremental innovations. They concluded that overlapping activities, inter-functional integration and teamwork positively could affect NPD performance based on development time and new product superiority for the case of incremental innovations and based on development cost in the case of radical innovations. They also concluded that CE should be used in the context or particular conditions, which characterize each innovation process. Grierson and Khajehpour (2002) used genetic algorithm as a meta-heuristic method for design of office buildings. Koski (1994) used heuristic method to select an appropriate design method. Grierson (2008) developed a new method for NPD using multiple objective criteria, which are conflicting in the sense of competing for common resources to achieve variously different performance objectives such as financial, functional, environmental, etc. The proposed MCDM strategy employs a tradeoff-analysis method to identify compromise designs for which the competing criteria are met in a Pareto-optimal sense. Grierson's MCDM technique was initially developed for the case of design governed by two objective criteria. It is then extended to design governed by more than two objective criteria, by presenting the concept of primary and aggregate criteria. There are some evidences to believe that from infinite number of feasible designs forming the Pareto front for a design problem governed by $n$ independent objective criteria, there is a unique Pareto-compromise design, which represents a mutually agreeable tradeoff among all $n$ criteria. Grierson (2008) demonstrated this idea for a flexural plate design governed by two criteria, a bridge maintenance-intervention protocol design governed by three criteria, and a media centre envelop design governed by eleven criteria.

In this paper, we present an empirical method for the case study of concurrent engineering for designing the pipes based on the implementation of the method proposed by Grierson (2008). The presentation of this paper first proposes Grierson's method in section 2 and the implementation of the case study is demonstrated in section 3. Finally, concluding remarks are given in section 4 to summarize the contribution of the paper. 


\section{Pareto optimal method}

\subsection{Pareto optimal definition}

In Multi-objective problems, a feasible solution, $A$, is called Pareto optimal if there is another feasible solution which is better than $A$ at least in terms of another objective. An optimal troubleshooting issue Pareto with $n$ objective functions can be demonstrated as follows:

$\min \left\{f_{1}(z), \cdots, f_{n}(z)\right\}$

subject to

$$
z \in \omega .
$$

where $f_{1}(z)$ to $f_{n}(z)$ are design objective functions based on different variables shown as technical vector topics as $z$. Let $z^{*}$ be the Pareto optimal solution then there exists $k$ objective functions such that we have,

$$
f_{i}(z) \leq f_{i}\left(z^{*}\right), \quad i=1, \cdots, k \leq n
$$

\subsection{Two criteria Pareto technique}

Let $A$ and $B$ be two designers who are completely in conflict with each other. Obviously, increasing on one objective function could result on losing optimality in other one, i.e.,

$$
f_{1}^{*}=\left(f_{1}^{\min }, \cdots, f_{1}^{\max }\right)^{\prime} \rightarrow \mathrm{f}_{2}^{*}=\left(f_{2}^{\max }, \cdots, f_{2}^{\text {min }}\right)^{\prime}
$$

In other words, let $f_{i}^{*}, i=1, \cdots m$ be the vector of Pareto optimal solutions, therefore we have,

$$
f_{1, j}^{*} \leq f_{1, j+1}^{*}, \quad f_{2, j}^{*} \leq f_{2, j+1}^{*} \quad j=1, \cdots, m
$$

Once the Pareto optimal solutions are determined, we may scale them using the following,

$$
x_{i}=\frac{f_{i}^{*}-f_{i}^{\min }}{f_{i}^{\max }-f_{i}^{\min }} \cdot \quad i=1, \cdots, n
$$

\subsection{The Grierson's two-dimensional method}

The first step of the proposed method developed by Grierson (2008) is to normalize all design alternatives using Eq. (5) and transfer the resulted normalized data into a two dimensional space by introducing the following,

$$
y_{i}=\frac{\sum_{k=1}^{n} x_{k}-x_{i}}{n-1} ; \quad i=1, \cdots, n
$$

Next, we calculate $x^{*}$ and $y^{*}$ using the following,

$$
\begin{aligned}
& x^{*}=\frac{x+\delta_{x}}{1+\delta_{x}}, \\
& y^{*}=\frac{y+\delta_{y}}{1+\delta_{y}},
\end{aligned}
$$

where $\delta_{x}=\sqrt{2}\left(x_{\max }-x_{\min }\right)-x_{\max }$ and $\delta_{y}=\sqrt{2}\left(y_{\max }-y_{\min }\right)-y_{\max }$. Based on Grierson's method, the efficient design yields equal values for $x^{*}$ and $y^{*}$. The relative importance of each attribute is calculated as follow, 


$$
\begin{aligned}
& \Delta x_{0}=\Delta y_{0}=0.5-\frac{\left(x_{j}^{*}+x_{j+1}^{*}\right)\left(y_{j}^{*}+y_{j+1}^{*}\right)}{x_{j}^{*}+x_{j+1}^{*}+y_{j}^{*}+y_{j+1}^{*}}, \\
& \Delta r_{0}=\sqrt{2} \Delta x_{0}=\sqrt{2} \Delta y_{0}, \\
& f^{0}=f^{\max }-\left(f^{\max }-f^{\min }\right)\left(\Delta r_{0}+\frac{\sqrt{2}}{2}\right) .
\end{aligned}
$$

In real-world case studies, we choose the alternatives with relatively close amount of values for $x^{*}$ and $y^{*}$. For more details on Grierson's method, the interested readers are referred to read his article (Grierson, 2008).

\section{Case study}

The case study of this paper is a real-world application of one of Iranian pipe production called Vahid Industrial Group (VIG) and it is located in one of Northern provinces of Iran, Mazandaran. The company produces polyethylene pipes in various diameters up to $250 \mathrm{~mm}$ size and the factory maintains a capacity of 500 tones. The firm's management considers the technological capabilities and competitive factors for producing polyethylene pipes. Therefore, a team composed of design staff, marketing, and production is gathered to select an appropriate design of the pipe in a concurrent engineering process.

\section{Table 1}

Input data

\begin{tabular}{ccccc}
\hline \multirow{2}{*}{ Designs \# } & \multicolumn{4}{c}{ Product features } \\
\cline { 2 - 5 } & Density $\left(\mathrm{gr} / \mathrm{cm}^{3}\right)$ & Tensile strength $\left(20^{0}\right)\left(\mathrm{N} / \mathrm{mm}^{2}\right)$ & Impact strength $\left(\mathrm{Kg} / \mathrm{mm}^{2}\right)$ & 25 \\
\hline 1 & 92.0 & 22 & 23 & 11 \\
2 & 925.0 & 8.22 & 5.21 & 2.10 \\
3 & 93.0 & 1.23 & 19 & 8.9 \\
4 & 937.0 & 3.23 & 18 & 9 \\
5 & 941.0 & 9.23 & 5.17 & 3.8 \\
6 & 944.0 & 3.24 & 16 & 7 \\
7 & 946.0 & 25 & 2.15 & 9 \\
8 & 95.0 & 3.26 & 5.14 & 5.9 \\
9 & 956.0 & 4.27 & 8.13 & 13 \\
10 & 958.0 & 28 & 13 & 5.10 \\
11 & 961.0 & 1.29 & 12 & 11 \\
12 & 9635.0 & 30 & & 6.11 \\
\hline
\end{tabular}

Since the concurrent team members were from different fields, it was important to establish a synergy among these people such that we could end up having common criteria to be measured for our study. Three groups of criteria are considered as the most important affecting factors which are cost, quality and capacity. Quality factor is considered by marketing and design sectors and cost is considered by production and financial sectors and production rate is considered by marketing and production sectors. A comprehensive review on all influencing factors reveals that there are different important factors influencing the selection of our final design. This includes flammable, color, density, tensile strength, yield stress, coefficient of flexibility, elongation, impact strength, thermal conductivity, hardness and PH range. Since there is a limit on the budget of this research study, we have selected density, two pressure factors and the amount of time needed to one meter in each design alternative as the most essential factors. Table 1 summarizes the input data of these four attributes for twelve design alternatives.

Note that the first objective, density, is on the form of the maximization and the other three are of the forms of minimization. Therefore, we need to consider a negative sign for three minimization objectives. For the case study of our proposed model we first normalize all four criteria based on Eq. 
(5) and transfer them into two dimensional space using Eq. (6) and Eq. (7) which are summarized in Table 2.

\section{Table 2}

The coordinate PC curve in two dimensional space

\begin{tabular}{llllllllllll}
\hline & $\begin{array}{l}\text { Density } \\
\left(\mathrm{gr} / \mathrm{cm}^{3}\right)\end{array}$ & & \multicolumn{3}{c}{$\begin{array}{l}\text { Tensile strength } \\
\left(20^{0}\right)\left(\mathrm{N} / \mathrm{mm}^{2}\right)\end{array}$} & \multicolumn{3}{c}{$\begin{array}{l}\text { Impact strength } \\
\left(\mathrm{Kg} / \mathrm{mm}^{2}\right)\end{array}$} & & Time & \\
\hline $\mathrm{D \# \#}$ & $\mathrm{X}^{*}$ & $\mathrm{Y}^{*}$ & $\mathrm{D} \#$ & $\mathrm{X}^{*}$ & $\mathrm{Y}^{*}$ & $\mathrm{D} \#$ & $\mathrm{X}^{*}$ & $\mathrm{Y}^{*}$ & $\mathrm{D} \#$ & $\mathrm{X}^{*}$ & $\mathrm{Y}^{*}$ \\
\hline 12 & 0.292893 & 1 & 1 & 0.292893 & 1 & 12 & 0.292893 & 1 & 1 & 0.292893 & 1 \\
1 & 0.385125 & 0.891688 & 2 & 0.372443 & 0.679555 & 11 & 0.401679 & 0.674116 & 2 & 0.385125 & 0.722596 \\
11 & 0.385125 & 0.832476 & 3 & 0.46967 & 0.629183 & 10 & 0.483268 & 0.62941 & 3 & 0.385125 & 0.699253 \\
10 & 0.461984 & 0.813892 & 4 & 0.522703 & 0.616491 & $\mathbf{9}$ & $\mathbf{0 . 6 1 9 2 5}$ & $\mathbf{0 . 6 2 3 5 1 7}$ & 4 & 0.461984 & 0.680668 \\
2 & 0.5081 & 0.757903 & 5 & $\mathbf{0 . 6 1 9 9 3}$ & $\mathbf{0 . 5 7 8 1 8}$ & 8 & $\mathbf{0 . 6 7 3 6 4 3}$ & $\mathbf{0 . 5 8 0 2 2}$ & 5 & 0.5081 & 0.6503 \\
9 & 0.538843 & 0.716241 & 6 & $\mathbf{0 . 7 3 4 8 3 5}$ & $\mathbf{0 . 5 4 8 3 0 3}$ & 7 & 0.700839 & 0.553063 & 6 & 0.538843 & 0.624009 \\
3 & 0.569587 & 0.658173 & 7 & 0.796707 & 0.510859 & 6 & 0.782429 & 0.52219 & $\mathbf{7}$ & $\mathbf{0 . 5 6 9 5 8 7}$ & $\mathbf{0 . 5 7 6 1 8 9}$ \\
$\mathbf{8}$ & $\mathbf{0 . 6 1 5 7 0 3}$ & $\mathbf{0 . 6 0 0 5 5 8}$ & 8 & 0.832062 & 0.491545 & 5 & 0.825943 & 0.473641 & 8 & $\mathbf{0 . 6 1 5 7 0 3}$ & $\mathbf{0 . 5 2 8 8 2 2}$ \\
4 & $\mathbf{0 . 6 9 2 5 6 2}$ & $\mathbf{0 . 5 3 4 6 4 6}$ & 9 & 0.885095 & 0.458042 & 4 & 0.864018 & 0.42586 & 9 & 0.692562 & 0.478282 \\
7 & 0.692562 & 0.446021 & 10 & 0.902773 & 0.387095 & 3 & 0.902093 & 0.382563 & 10 & 0.692562 & 0.415277 \\
5 & 0.800165 & 0.386415 & 11 & 0.929289 & 0.359899 & 2 & 0.945607 & 0.350153 & 11 & 0.800165 & 0.355672 \\
6 & 1 & 0.292893 & 12 & 1 & 0.292893 & 1 & 1 & 0.292893 & 12 & 1 & 0.292893 \\
\hline D\#: Design number, Bold numbers are used in Eq. (9) for the calculation of the relative importance of each attribute. & & & &
\end{tabular}

The relative importance of each attributes is calculated based on Eq. (8-10) as follows,

$f_{1}^{0}=0.938705, f_{2}^{0}=18.3545, f_{3}^{0}=15.7324, f_{4}^{0}=7.48865$.

As we can observe, design number 8 is the preferred one based on density characteristic, design number 5 is the preferable one based on tensile strength, design numbers 9 and 7 are also considered the best based on impact strength and production rate, respectively.

One important question is to find the best possible alternative based on four attributes. There are different methods to choose the appropriate alternative design is to use mean square error (MSE) as follows,

$$
\operatorname{MSE}_{j}=\frac{1}{n} \sum_{i=1}^{n}\left(1-\frac{f_{i}}{f^{0}}\right), j=1, \cdots, m
$$

where $f_{i}$ are the attributes associated with different design alternatives given in Table 1 and $f^{0}$ is the result of the implementation of Grierson (2008). Table 3 summarizes the results of our MSE for all twelve alternative designs.

Table 3

The MSE results

\begin{tabular}{lcccccccccccc}
\hline D\# & 1 & 2 & 3 & 4 & 5 & 6 & 7 & 8 & 9 & 10 & 11 & 12 \\
\hline MSE & 81 & 5004 & 68 & 5160 & 5183 & 5227 & 5260 & 55 & 5379 & 5377 & 5443 & 550945 \\
\hline
\end{tabular}

As we can observe from Table 3, alternative 8 represents the minimum MSE and it is chosen as the best design alternative, and alternative 3 and 1 come after with relatively small MSE difference.

\section{Conclusions}

In this paper, we have presented an empirical method for case study of polyethylene pipes. The primary aim of this research was to choose an alternative design among various available one. In our study, we gathered different team members in a concurrent engineering team who were actively working for a pipeline production and chose the most important factors involved in designing pipeline. We have also used Grierson's method two-dimensional MCDM method to find the most 
appropriate design alternative based on various attributes and used a mean square error to rank different alternatives based on all existing criteria. The results indicated that Grierson's method could be easily used for problems with various alternative design, successfully.

\section{References}

Agrell, P. J. (1994). A multicriteria approach to concurrent engineering. International Journal of Production Economics, 34(1), 99-113.

Brookes, N.J., Backhouse, C.J. (1998). Understanding concurrent engineering implementation: a case-study approach, International Journal of Production Research, 3035-3054.

Grierson, D. E. \& Khajehpour, S. (2002). Method for conceptual design applied to office buildings. Journal of Computing in Civil Engineering, ASCE, 16 (2), 83-103.

Grierson, D. E. (2008). Pareto multi-criteria decision making. Journal of advanced engineering informatics, 22 (3), 371-384.

Hokkanen, J., \& Salminen, P. (1993). Applying multiple criteria aid for decision to environmental management. London: Kluwer Academic Publishers.

Koski, J. (1994). Multicriterion structural optimization, Advances in Design Optimization, 194-224, chapter 6.

Liu, H. T. (2011). Product design and selection using fuzzy QFD and fuzzy MCDM approaches. Applied Mathematical Modelling, 35(1), 482-496.

Qi, J., Hu, J., Peng, Y. H., Wang, W., \& Zhang, Z. (2009). A case retrieval method combined with similarity measurement and multi-criteria decision making for concurrent design. Expert Systems with Applications, 36(7), 10357-10366.

Rahimi-Vahed, A. R., Rabbani, M., Tavakkoli-Moghaddam, R., Torabi, S. A., \& Jolai, F. (2007). A multi-objective scatter search for a mixed-model assembly line sequencing problem. Advanced Engineering Informatics, 21, 85-99.

Valle, S., \& Vasquez-Bustelo, D. (2009). Concurrent engineering performance: Incremental versus radical innovation. International Journal of Production Economics, 119(1), 136-148.

Winner, R.I., Pennell, J.P., Bertend, H.E., \& Slusarczuk, M.M.G. (1988). The role of concurrent engineering in weapon system acquisition, Institute for Defence Systems Analysis, Alexandria, Virginia. 